Journal of Social Sciences 4 (4): 264-271, 2008

ISSN 1549-3652

(C) 2008 Science Publications

\title{
An Econometric Model for Water Sector in Jordan
}

\author{
Mohammed Issa Shahateet \\ Princess Sumaya University of Technology \\ P.O. Box 1438, Amman 11941, Jordan
}

\begin{abstract}
Problem statement: This study argued that there is an economic approach to reduce water problems faced by Jordan. The study took into consideration the increasing population size, the declining rainfall, a deepening shortage of supply and increasing demand for water, the production of agricultural and industrial sectors, price of unit exports, and lack of financial resources. Approach: The framework for a tool which takes into consideration the links between economic growth and the availability of water was developed in this study, in the form of a dynamic simulation econometric model. The model served as a quantitative tool to evaluate the water policy measures and forecast the effect of future policy variables on the water status in Jordan. Results: Agricultural, industrial and other types of production are affected by water uses which in turn are influenced by production and other socioeconomic variables, including population size, the extent of production market, and the size of linkage effects working through certain increases in water consumption. The results also showed the model can be used to solve key issues related to the formulation and implementation of water policy. They also identified lessons for water management policy within a broad socio-economic perspective. Conclusions: First, with regard to production sector, a major effect can be attributed to the supply of water. Second, gross domestic products of agricultural, industrial and other sectors were found to be highly significant factors in influencing the supply of water. Finally, priorities for making the most of Jordan's water resources should be given to options affecting water-supply strategy which relates the supply of water to the level of production.
\end{abstract}

Key words: Econometric models, economics of water, water modelling

\section{INTRODUCTION}

The effect of water on economic growth is beyond emphasis. Economic growth rates are affected, among other things, by scarcity of water. Both water demand and supply, on the other hand, are also influenced by the level of production and other socio-economic variables. This interrelationship between economic variables and water scarcity has been neglected in econometric literature. The reason behind this negligence could be attributed to the fact that economic models were built in developed countries which do not face serious water shortage problems. However, in developing countries the situation is rather different. Water is the sine qua non of development and a critical issue not only in making decisions concerning agricultural investment but also in most socioeconomic factors.

Water resources in Jordan have considerably decreased since 1980. Irregular rainfalls, mismanagement of water resources and factors of high population growth had aggravated the water deficiency. These facts have been emphasized by many studies, especially a study which examined the economic importance of water, problems of water supply and water quality, and regional conflicts over water. ${ }^{[1]}$ Other studies emphasized the role of water as a key factor in creating and sustaining peace and hence paving the way to economic growth ${ }^{[2]}$. Most studies that addressed water problem in Jordan have concentrated on technical, rather than economic, issues such as quality of water, utilization of water resources, conservation and reuse of water and water saving technology. Few studies, however, addressed economic issues related to water, such as estimating irrigation water demand function and its price elasticity ${ }^{[3]}$ and estimating demand and supply functions for drinking water $^{[4]}$. From the socioeconomic point of view, the challenging problems that face Jordan are unemployment, poverty and low productivity especially in agricultural and services sectors. These problems make it necessary to search for solutions for the nagging water problem.

The contributions of this research are three-fold. First, it examines the available options and the experience of Jordan's management of water problem and suggests an economic approach to reduce water 
problems, through developing an econometric model suitable for evaluating water policies. Second, it links future economic and social developments with water availability and measures these developments through a simulation process. Finally, it views water as a production factor.

The status of water sector in Jordan: During the last two decades, the expected loads of rain that normally refill the dams, the Jordan River and the underground natural water storages did not meet the demand for water. To cope with the threatening water scarcity each summer, a rigorous water-rationing schedule is put in place for households, farmers and industries. While tentative water rationing schedules are altered frequently according to rainfall received and depending on estimates of water availability during summer, the rationing plan for cities generally remains unchanged because drinking water supply to municipalities has priority.As a developing economy, a large proportion of the labor force is engaged in agriculture that consumes most of the country's water supply. From 2002-2007, annual GDP growth rates at constant prices were, on average, $5.7 \%$. Furthermore, the poor management of water and the fluctuations of rainfall have resulted in a decreasing agricultural production per capita and a decline in per capita consumption of water. From 20022007 , the average growth rate of agricultural sector was negative, at $-2.6 \%{ }^{[5]}$. The per capita consumption of water in Jordan, estimated between 70 and 75 liters per day, has reached alarming scarcity compared to what is internationally conceived as adequate water consumption at 200 liters per day. Water use in Jordan, as in many other developing countries in the region, is dominated by agriculture, which poses the biggest threat to water resources. Agricultural water, used mostly for irrigation and livestock, accounts for almost $70 \%$ of the total demand for water, but returns less than five per cent to the national economy. The gulf between agricultural consumption and contribution to the GDP has led economists and agriculture experts to advocate reducing agriculture's water allocation. Industrial water use in Jordan accounts for approximately $9 \%$ of consumption and is concentrated in certain geographic regions mainly Amman, Zarka and Irbid governorates. Municipal uses of water include supply to the domestic sector, as well as to commercial buildings and to washing facilities. Municipal use represents the second largest use, at $7 \%$.

At the planning level, several policies have been suggested to reduce Jordan's grim dilemma of water shortage. Jordan suggested a comprehensive water management plan in five priority action areas, as follows:

- Reduce the water demand

- Encourage appropriate private sector participation in water resource management

- Create real incentives to encourage efficient water conservation and discourage waste including enforcing fully the existing regulations on water use and develop legislation to close gaps in the laws

- Build and maintain a public opinion setting in which knowledge of this vital resource and the means of conserving it stay on the agenda of groups and individuals throughout the land

- Strengthen the capability of water-related institutions so they can develop and fully implement sound water policies and programs

At the implementation level, solutions to the problem of domestic water supply in Jordan have been many and varied. On the supply side, the solutions include the expansion of conventional supplies through increased damming of rivers and streams and development of boreholes on a large scale, typically in combination with damming and recycling wastewater. On the demand side, solutions include establishing seasonal quotas and usage restrictions, rationing by time of day or area and setting price penalties. Efforts to resolve the above-mentioned problems have focused almost exclusively on the development of additional water supplies. The governmental institutions that have evolved to deal with water scarcity have been committed to the construction of storage and conveyance facilities (primarily for irrigation), while at the same time neglecting to deal fully with groundwater over-extraction and related environmental problems.

Policies affecting the demand for water emphasized that the demand is influenced by increased irrigation, rapidly increasing population and industrial development. Policies designed to reduce the demand for water had concentrated on the following activities:

- A nationwide publicity programmes aiming at educating consumers about vitality of water. These programmes are carried out through mass media

- Privatizing water management in co-operation with strategic partners

- Restricting cultivation of water-consuming crops

- Reforming water subsidies (water pricing) 
Policies affecting the supply of water affirmed that the major supply options for Jordan include building more dams for storing water, improving conveyance and distribution structures, reducing leaks and reusing wastewater. Nationwide, most of the initial increased supply would come from reusing wastewater, building new dams and reducing losses from leaks. In sum, these policies have concentrated on the following activities:

- Building reservoirs

- Treating and reusing wastewater

- Controlling the use of groundwater

- Preventing leaks in water delivery systems

- Maintaining environmental protection of water

The experience of Jordan in applying these policies does not seem to have participated in solving the shortage of water, although these options were not fully implemented. In fact, various causes have prevented full compliance, including lack of financial and human resources and higher policy priorities. As a result, the problem of a water deficit persists and deepens. Population growth, improvement of the living standards and development of irrigation and industry have increased pressure on the natural resources of water. Moreover, mobilisation of new water resources is technically more and more difficult and expensive. In order to face these challenges, a comprehensive and sustainable development of the water resources is essential for the social and economic development of the country. Expansion of the irrigated area will continue with increasing demand for food and from the development of agricultural production for export markets. Irrigation is one of the ways to increase agricultural productivity.

\section{MATERIALS AND METHODS}

Water modellers focused on interregional concerns: specifically, developing methods to analyse the distributional implications of water policies. Dynamic models, as opposed to static models, allow for or explain changes in the values of endogenous variables as time passes, even when there are no changes in the economic structure or exogenous variables (except time). That is, no changes in behaviour patterns or institutional or technological conditions or policy. These models also assert that scarcity of water is not entirely due to natural phenomena but also due to high population and economic growths. These determinants of scarcity are likely to increase in the future with growth in economic activities both in the agricultural and in the industrial sectors. Many empirical studies of the impact of water management on the economy have sought to correlate the impact of investments in water projects with GDP growth at the micro-economic level.

This research has been profoundly influenced by the dynamic econometric approach which looks at water as an additional factor input in agricultural, industrial and other types of production function relating GDP to the use of water and capital. The approach is firmly in the tradition of broad capital approaches to economic growth and seeks to model the implications of water for productivity. Indeed, in pursuing relations at the aggregate level, the model explicitly identifies the way in which aggregate economic variables affect water and vice versa. During the last two decades, many studies have been devoted to the estimation of residential water demand, or supply, functions. Most applied studies of water models are focussed on areas of $\mathrm{China}^{[6]}$, the $\mathrm{USA}^{[7-8]}$ and Europe $^{[9]}$. Empirical evidence stemming from developing countries is very scarce. Econometric models have also been used for evaluating water pricing scenarios as a tool for better management of water consumption. In studying the demand for water, researchers have utilized a variety of statistical and econometric techniques and they have focused on finding the appropriate demand management policies that offer incentives in saving water ${ }^{[10]}$.

The model: The model comprises a system of equations that represents the production sector and the water sector.

The production sector is presented by three behavioural equations of the form:

$\mathrm{AP}_{\mathrm{t}}=\alpha_{0}+\alpha_{1} \mathrm{ACF}_{\mathrm{t}}+\alpha_{2} \mathrm{APE}_{\mathrm{t}}+\alpha_{3} \mathrm{AS}_{\mathrm{t}}+\alpha_{4} \mathrm{RF}_{\mathrm{t}}+\mathrm{u}_{\alpha}$

$\mathrm{IP}_{\mathrm{t}}=\beta_{0}+\beta_{1} \mathrm{ICF}_{\mathrm{t}}+\beta_{2} \mathrm{IPE}_{\mathrm{t}}+\beta_{3} \mathrm{IS}_{\mathrm{t}}+\mathrm{u}_{\beta}$

$\mathrm{OP}_{\mathrm{t}}=\gamma_{0}+\gamma_{1} \mathrm{OCF}_{\mathrm{t}}+\gamma_{2} \mathrm{OL}_{\mathrm{t}}+\mathrm{u}_{\gamma}$

Where:

$\mathrm{AP}=$ Agricultural production, at basic prices

$\mathrm{ACF}=$ Agricultural credit facilities issued by banks

APE = Agricultural unit price of exports

AS = Agricultural supply of water

$\mathrm{RF} \quad=$ Rainfall

IP = Industrial production, at basic prices

ICF = Industrial credit facilities issued by banks

IPE = Industrial unit price of exports

IS = Industrial supply of water

$\mathrm{OP}=$ Other types of production, at basic prices

$\mathrm{OCF}=$ Other credit facilities issued by banks

OL = Other types of labor. 
All Greek letters are parameters to be estimated and all u's are stochastic disturbance terms. Here, the total production is divided into three parts: Agricultural, industrial and others. Agricultural production Eq. 1 is assumed to be influenced by credit facilities extended, by banks, to agricultural sector, the price of agricultural unit of exports, water supply to agricultural sector and the quantity of rainfall. Industrial production Eq. 2 is assumed to be affected by credit facilities extended, by banks, to the industrial sector, the price of industrial unit of exports and water supply to industry. Finally, other types of production such as electricity, construction, trade and the like Eq. 3 are influenced by credit facilities extended to other economic activities (total activities(agriculture+industry)) and labor employed in these activities.

The water sector is expressed by three behavioural equations and two identities. The supply of water comprises the supply of water for three purposes: agricultural, industrial and municipal. Each type of these supplies is influenced by a set of socio-economic variables as described below.

$$
\begin{aligned}
& \mathrm{AS}_{\mathrm{t}}=\delta_{0}+\delta_{1} \mathrm{AP}_{\mathrm{t}}+\delta_{2} \mathrm{RF}_{\mathrm{t}}+\mathrm{u}_{\delta} \\
& \mathrm{IS}_{\mathrm{t}}=\zeta_{0}+\zeta_{1} \mathrm{IP}_{\mathrm{t}}+\zeta_{2} \mathrm{RF}_{\mathrm{t}}+\mathrm{u}_{\zeta} \\
& \mathrm{MS}_{\mathrm{t}}=\eta_{0}+\eta_{1} \mathrm{POP}_{\mathrm{t}}+\eta_{2} \mathrm{RF}_{\mathrm{t}}+\eta_{3} \mathrm{GDPPC}_{\mathrm{t}}+\mathrm{u}_{\eta} \\
& \mathrm{GDP}_{\mathrm{t}} \equiv \mathrm{AP}_{\mathrm{t}}+\mathrm{IP}_{\mathrm{t}}+\mathrm{OP}_{\mathrm{t}} \\
& \mathrm{SW}_{\mathrm{t}} \equiv \mathrm{AS}_{\mathrm{t}}+\mathrm{MS}_{\mathrm{t}}+\mathrm{IS}_{\mathrm{t}}
\end{aligned}
$$

Where:

$$
\begin{array}{ll}
\text { POP } & =\text { Population } \\
\text { GDP } & =\text { Gross domestic product }, \text { at basic prices } \\
\text { GDPPC } & =\text { Per capita gross domestic product } \\
\text { MS } & =\text { Municipal supply of water } \\
\text { SW } & =\text { Supply of water. }
\end{array}
$$

Again, all Greek letters are parameters to be estimated and all u's are stochastic disturbance terms. Here, the supply of water to agriculture Eq. 4 is assumed to be affected by the required volume of agricultural production and the quantity of rainfall. The supply of water to industrial sector Eq. 5 is assumed to be determined by industrial production and rainfall. Finally, municipal supply of water Eq. 6 is assumed to be affected by population size, rainfall and the level of real per capita GDP. It should be emphasized that the prices of water, in Jordan, are not, currently, determined by mere economic factors. Therefore, the supply of water can be considered inelastic to prices, which have a minor influence on the implementation of supply management strategies. It is not surprising that economic theory suggests that the supply of water should be price inelastic for three reasons: (1) there exist no close substitutes for water in most of its uses, (2) the amount of money spent on water is generally a relatively small share of the typical budget and, (3) water is frequently demanded jointly with some other complementary good. Theoretically, the long run equilibrium condition implies that the demand for water is equal to the supply of water. That is, $\mathrm{DW}_{\mathrm{t}} \equiv \mathrm{SW}_{\mathrm{t}}$. However, this identity is not integrated into the model since disequilibrium may hold in this context.

Data and estimation technique: The data requirements for the model include time-series variables. The relevant time series variables are annual data, from official sources, expanding from 1970-2006. The estimation process comprises two consecutive steps. The first involves selecting the model from a rough class of models that better describes the behaviour of the variables under study, in statistical sense. The tentative model is then fitted to the data and the estimated parameters are obtained by applying the method of ordinary least squares, OLS. Often, the OLS assumption that the model's residuals are independent must be abandoned in the face of evidence that each residual is dependent on the residuals in the time period preceding it. A test for the presence of autocorrelation is carried out. When the model exhibits autocorrelation, this research applies Cochrane-Orcutt technique. If each residual is presumed to be dependent only on the residual immediately before it we apply first-order autoregressive process, AR (1), which drops the first observation. If each residual depends on the two previous ones, then we speak of second-order autocorrelation and hence we apply AR (2) which drops the first two observations, as shown in Tables 1-6. Naturally, common diagnostic checks for model selection were applied for testing the appropriateness of the model. Obviously, each step is repeated several times until the standard econometric conditions are satisfied. When adequate rules of model selection are satisfied, the model is used in the second step.

In the second step, the rough estimates that were obtained by OLS, with or without correction of the autocorrelation, were used as starting values for estimating the parameters of the model using the full information maximum likelihood, FIML, estimation approach. Here, new estimates of the parameters are obtained by running the model again on equations 
containing the respective transformed series to produce dynamic simulations. The AR coefficient is then recalculated and the variable transformations are done. The whole process is repeated until the change between successive values of the AR coefficient is smaller than an assumed convergence criterion (0.001) or a maximum number of iterations (50) is reached. In the second step, the maximum-likelihood technique does not drop the first or second observation, as do the Cochrane-Orcutt technique, which was used in the first step.

The algorithm used in simulation is Gauss-Seidel, with successive over- and under-relaxation. In this case, subsets of equations which only depend on equations previously solved in the time period, exogenous variables and lagged endogenous variables are segregated into recursive blocks, behind any simultaneous blocks which have already been solved.
The simultaneous blocks contain subsets of equations which are inter-dependent, so that no one can be solved in isolation, even with previously solved, exogenous and lagged endogenous variables.

\section{RESULTS}

A summary of the estimated parameters, obtained in the first step of estimation, along with other main regression results are presented in Tables 1-6. For each behavioural equation, tens of empirical attempts were made to select the appropriate model, but only the most proper three models are shown. In Tables 1-6, the regression estimates of the selected models (Model III in each Table) are consistent with economic theory and they appear very reasonable from many angles, including the expected signs, significance level, log likelihood, Durbin-Watson statistic and adjusted $\mathrm{R}^{2}$.

Table 1: Regression results for agricultural production, AP estimated parameters and t-statistics (In parentheses)

\begin{tabular}{|c|c|c|c|c|}
\hline Explanatory variable & Coefficient & Model I AR(2) & Model II AR(2) & Model III AR(2) \\
\hline Constant & $\alpha_{0}$ & $-26.17720000(-0.572841)$ & $81.1697000 * *(2.22544)$ & $-33.57860(-0.674138)$ \\
\hline $\mathrm{ACF}$ & $\alpha_{1}$ & $0.822517 * * *(3.30082)$ & $0.831227 * * *(2.70066)$ & $0.786732 * * *(2.56830)$ \\
\hline APE & $\alpha_{2}$ & & $-0.134804000(-0.644177)$ & $0.046510(0.221120)$ \\
\hline AS & $\alpha_{3}$ & $0.162073 *(1.86591)$ & & $0.172717 *(1.89314)$ \\
\hline RF & $\alpha_{4}$ & $0.003699 * * *(4.24931)$ & $0.0035340 * * *(4.17480)$ & $0.003704 * * *(4.14581)$ \\
\hline Log (likelihood) & & -149.519000 & -150.631000 & -149.497000 \\
\hline Schwarz Criterion & & -156.630000 & -157.742000 & -158.385000 \\
\hline Akaike Criterion & & -153.519000 & -154.631000 & -154.497000 \\
\hline Durbin-Watson & & 1.952930 & 2.034150 & 1.955240 \\
\hline Adjusted $\mathrm{R}^{2}$ & & 0.919500 & 0.914200 & 0.916900 \\
\hline $\mathrm{N}$ & & 35.000000 & 35.000000 & 35.000000 \\
\hline
\end{tabular}

*,** and $* * *:$ Significant at the 10,5 , and $1 \%$ level, respectively.

Table 2: Regression results for industrial production, IP estimated parameters and t-statistics (In parentheses)

\begin{tabular}{|c|c|c|c|c|}
\hline Explanatory variable & Coefficient & Model I AR(2) & Model II AR(2) & Model III AR(2) \\
\hline Constant & $\beta_{0}$ & $41.947900(0.581546)$ & $17.689700(0.290287)$ & $42.365600(0.525791)$ \\
\hline IS & $\beta_{1}$ & $3.46999 *(1.91516)$ & $3.38925 *(1.97112)$ & $3.46026^{*}(1.79500)$ \\
\hline $\mathrm{ICF}$ & $\beta_{2}$ & $1.53246^{* * *}(14.1989)$ & & $1.53368 * * *(11.2568)$ \\
\hline IPE & $\beta_{3}$ & & $1.61128 * *(2.28679)$ & $0.01323(0.0139605)$ \\
\hline Log (likelihood) & & -180.31300 & -180.93300 & -180.31300 \\
\hline Schwarz Criterion & & -185.64600 & -186.22600 & -187.42300 \\
\hline Akaike Criterion & & -183.31300 & -183.93300 & -184.31300 \\
\hline Durbin-Watson & & 2.05492 & 1.94281 & 2.05618 \\
\hline Adjusted $\mathrm{R}^{2}$ & & 0.98990 & 0.98950 & 0.98960 \\
\hline $\mathrm{N}$ & & 35.00000 & 35.00000 & 35.00000 \\
\hline
\end{tabular}

$*, * *$ and $* * *:$ Significant at the 10,5 , and $1 \%$ level, respectively.

Table 3: Regression results for other categories of production, OP estimated parameters and t-statistics (In parentheses)

\begin{tabular}{|c|c|c|c|c|}
\hline Explanatory variable & Coefficient & Model I AR(2) & Model II AR(2) & Model III OLS \\
\hline Constant & $\gamma_{0}$ & $821.008000 *(1.90877)$ & $13278.700000 * * *(3.22710)$ & $-14.04070(-0.717253)$ \\
\hline $\mathrm{OCF}$ & $\gamma_{1}$ & & $0.228304 * * *(4.01698)$ & $0.09184 * * *(2.77455)$ \\
\hline OL & $\gamma_{2}$ & $0.719881 * * *(24.4055)$ & & $0.874226 * * *(30.8113)$ \\
\hline Log (likelihood) & & -177.76700 & -201.96700 & -197.38800 \\
\hline Schwarz Criterion & & -181.32200 & -205.53200 & -200.99900 \\
\hline Akaike Criterion & & -179.76700 & -203.96700 & -199.38800 \\
\hline Durbin-Watson & & 1.98903 & 2.21893 & 0.54419 \\
\hline Adjusted $\mathrm{R}^{2}$ & & 0.99950 & 0.99820 & 0.73820 \\
\hline $\mathrm{N}$ & & 35.00000 & 35.00000 & 37.00000 \\
\hline
\end{tabular}

*,** and ***: Significant at the 10,5 , and $1 \%$ level, respectively. 
J. Social Sci., 4 (4): 264-271, 2008

Table 4: Regression results for agricultural supply of water, AS estimated parameters and t-statistics (In parentheses)

\begin{tabular}{llccc}
\hline Explanatory variable & Coefficient & Model I AR(2) & Model II OLS & Model III OLS \\
\hline Constant & $\delta_{0}$ & $474.404^{* * *}(8.91713)$ & $440.876^{* * *}(18.4330)$ & $358.680^{* * *}(20.1669)$ \\
AP & $\delta_{1}$ & $0.545083^{* *}(2.29609)$ & & $1.47770^{* * *}(7.89358)$ \\
APE & $\delta_{2}$ & -170.90200 & $1.10858^{* * *}(4.01215)$ & $0.329513(1.33485)$ \\
Log (likelihood) & & -174.45800 & -218.91400 & -196.44300 \\
Schwarz Criterion & -172.90200 & -219.31600 & -201.85900 \\
Akaike Criterion & 2.01131 & -217.70500 & -199.44300 \\
Durbin-Watson & 0.88040 & 1.96033 & 2.00764 \\
Adjusted R & & 35.00000 & 0.86900 & 0.87950 \\
$\mathrm{~N}$ & & 37.00000 & 37.00000 \\
* $^{* *}$ and ***: Significant at the 10, 5, and 1\% level, respectively.
\end{tabular}

Table 5: Regression results for industrial supply of water, IS estimated parameters and t-statistics (in parentheses)

\begin{tabular}{llccc}
\hline Explanatory variable & Coefficient & Model I OLS & Model II AR (2) & Model III OLS \\
\hline Constant & $\zeta_{0}$ & $14.6740^{* * *}(6.76361)$ & $43.0526^{* * *}(3.78369)$ & $12.7760^{* *}(2.04551)$ \\
IP & $\zeta_{1}$ & $0.022187^{* * *}(6.24275)$ & & $0.022385^{* * *}(6.12985)$ \\
RF & $\zeta_{2}$ & -133.82000 & $0.000135(0.58753)$ & $0.000230(0.32439)$ \\
Log (likelihood) & & -137.43100 & -95.89000 & -133.76300 \\
Schwarz Criterion & -135.82000 & -99.44540 & -139.17900 \\
Akaike Criterion & 1.96807 & -97.89000 & -136.76300 \\
Durbin-Watson & 0.91150 & 1.97723 & 1.95643 \\
Adjusted R & & 37.00000 & 0.91010 & 0.90930 \\
$\mathrm{~N}$ & & 35.00000 & 37.00000 \\
\hline *** and ***: Significant at the 10, 5, and 1\% level, respectively. & &
\end{tabular}

Table 6: Regression results for municipal supply of water, MS estimated parameters and t-statistics (In parentheses)

\begin{tabular}{llccc}
\hline Explanatory variable & Coefficient & Model I AR (2) & Model II AR (2) & Model III AR (1) \\
\hline Constant & $\eta_{0}$ & $-62.3014 * * *(-2.78102)$ & $882.481 * * *(5.22621)$ & $-71.4093 * * *(-3.06480)$ \\
POP & $\eta_{1}$ & $0.064139 * * *(11.4892)$ & & $0.064522 * * *(11.5152)$ \\
RF & $\eta_{2}$ & -128.89400 & $0.000913 *(1.73634)$ & $0.000945 *(1.67493)$ \\
Log (likelihood) & & -132.45000 & -128.54700 & -130.75600 \\
Schwarz Criterion & & -130.89400 & -132.10200 & -136.13100 \\
Akaike Criterion & & -130.54700 & -133.75600 \\
Durbin-Watson & & 2.00435 & 0.02446 & 1.88840 \\
Adjusted R & & 0.98700 & 35.00000 & 0.98820 \\
$\mathrm{~N}$ & & 35.00000 & & 36.00000 \\
\hline
\end{tabular}

*, ** and $* * *$ Significant at the 10,5 , and $1 \%$ level, respectively.

\section{DISCUSSION}

Although the above estimates of the coefficients are of moderate importance since they will be used as initial estimates in the second step of estimation, the overall regression results for the production sector, shown in Tables 1-3, were adequate; with most of the individual coefficients are significant, having the expected sign, high values of adjusted $\mathrm{R}^{2}$ and no autocorrelation among residuals. As expected, the most influencing variables on agricultural production are rainfall, credit facilities extended by banks and the supply of water to agricultural sector. Moreover, the price of unit exports of agricultural production did not significantly affect the agricultural production. However, it was taken into consideration in the second step despite its minor effect, as in economic literature producers are assumed to be positively influenced by the prices of unit export of agricultural goods. Other variables such as agricultural labor, area of irrigated land and lagged values of the explanatory variables were considered in our early attempts to find a good model but the results were not satisfactory. The results of the model indicate that credit facilities extended by banks, a proxy for capital flows, is the main determinant of industrial production. The supply of water to industry is significant at $10 \%$ level indicating a lesser importance. Adjusted $\mathrm{R}^{2}$, the log likelihood and Durbin-Watson statistics are all in line with high degree of model performance. Other types of production are influenced by labor and capital flows, represented by credit facilities extended. Each variable is significant at the $1 \%$ level and has the expected positive sign.

The estimation results for the equations of water sector, shown in Tables 4-6, indicate good model performance. All coefficients generally exhibit expected signs and are statistically significant. More precisely, agricultural supply of water is mainly determined by the level of agricultural production as it is significant at the $1 \%$ level. This also indicates 
recursive behaviour of the water and production sectors. Other statistics, in Table 4, are self explanatory. Regression results of industrial supply of water, shown in Table 5, also show that industrial production is the main determinant, as it is significant at the $1 \%$ level with a positive sign. Again, all other statistics are highly acceptable. The economic variables hypothesised to influence municipal water consumption (population size, rainfall and real per capita GDP) are significant except the latter which did not enhance the performance of the model. Perhaps, its effect is captured by the other two variables. Hence, it was omitted from Eq. 6.
The results of the second step of estimation, which involves the application of FIML technique, are shown in Table 7. As can be seen, out of 21 parameters, 14, 1 and 3 are significant at the 1, 5 and $10 \%$ level, respectively. This leaves only 3 parameters insignificant. However, the overall results are satisfactory.

Dynamic simulations of the model: Simulation tools are used to model the water management dynamics on real-world system. Their use supports policy-makers to

Table 7: Main regression results of FIML, 1970-2006

\begin{tabular}{|c|c|c|c|c|}
\hline \multirow{2}{*}{$\begin{array}{l}\text { Variable } \\
\text { coefficient }\end{array}$} & \multirow{2}{*}{$\begin{array}{c}\text { Starting value OLS } \\
\text { Coefficient }\end{array}$} & \multicolumn{3}{|c|}{ Final value FIML } \\
\hline & & Coefficient & t-value & Level of significance \\
\hline$\overline{\alpha_{0}}$ & -33.578600 & -32.2673000 & -32.04990 & 0.000 \\
\hline$\alpha_{1}$ & 0.786732 & 0.1516510 & 9.63613 & 0.000 \\
\hline$\alpha_{2}$ & 0.046510 & 0.0017280 & 1.17166 & 0.249 \\
\hline$\alpha_{3}$ & 0.172717 & 0.1600860 & 1.15629 & 0.255 \\
\hline$\alpha_{4}$ & 0.003704 & 0.4909500 & 3.97430 & 0.001 \\
\hline$\beta_{0}$ & 42.365600 & 43.4468000 & 43.00200 & 0.000 \\
\hline$\beta_{1}$ & 3.460260 & 4.4601800 & 3.73759 & 0.001 \\
\hline$\beta_{2}$ & 1.533680 & 1.1914200 & 25.06930 & 0.000 \\
\hline$\beta_{3}$ & 0.013230 & 0.6507140 & 1.74493 & 0.089 \\
\hline$\gamma_{0}$ & -14.040700 & -13.7012000 & -13.45380 & 0.000 \\
\hline$\gamma_{1}$ & 0.091840 & 0.0235750 & 1.71422 & 0.095 \\
\hline$\gamma_{2}$ & 0.874226 & 0.8246570 & 74.90370 & 0.000 \\
\hline$\delta_{0}$ & 358.680000 & 358.7850000 & 358.49300 & 0.000 \\
\hline$\delta_{1}$ & 1.477700 & 1.4749300 & 8.88536 & 0.000 \\
\hline$\delta_{2}$ & 0.329513 & 0.3149810 & 1.24010 & 0.223 \\
\hline$\zeta_{0}$ & 12.776000 & 5.4073600 & 1.93947 & 0.060 \\
\hline$\zeta_{1}$ & 0.022385 & 0.0429820 & 6.27703 & 0.000 \\
\hline$\zeta_{2}$ & 0.000230 & 0.0016740 & 6.11651 & 0.000 \\
\hline$\eta_{0}$ & -71.409300 & -72.2330000 & -60.09830 & 0.000 \\
\hline$\eta_{1}$ & 0.064522 & 0.0638590 & 43.73960 & 0.000 \\
\hline$\eta_{2}$ & 0.000945 & 0.0015318 & 2.28939 & 0.028 \\
\hline
\end{tabular}

Note: levels of significance for the OLS estimates are shown in Tables 1-6

Table 8: Simulation results, 2009-2015

\begin{tabular}{|c|c|c|c|c|c|c|}
\hline Year & $\begin{array}{l}\text { Agricultural } \\
\text { Production (AP) }\end{array}$ & $\begin{array}{l}\text { Industrial } \\
\text { production (IP) }\end{array}$ & $\begin{array}{l}\text { Other types } \\
\text { of production (OP) }\end{array}$ & $\begin{array}{l}\text { Agricultural supply } \\
\text { of water (AS) }\end{array}$ & $\begin{array}{l}\text { Industrial supply } \\
\text { of water (IS) }\end{array}$ & $\begin{array}{l}\text { Municipal supply } \\
\text { of water (MS) }\end{array}$ \\
\hline 2009 & 369.55 & 2202.23 & 8506.70 & 660.58 & 39.276 & 327.296 \\
\hline 2010 & 401.46 & 2381.26 & 9064.32 & 682.61 & 39.672 & 338.012 \\
\hline 2011 & 433.37 & 2560.29 & 9621.94 & 704.64 & 40.068 & 348.728 \\
\hline 2012 & 465.28 & 2739.32 & 10179.6 & 726.67 & 40.464 & 359.444 \\
\hline 2013 & 497.19 & 2918.35 & 10737.2 & 748.70 & 40.860 & 370.160 \\
\hline 2014 & 529.10 & 3097.38 & 11294.8 & 770.73 & 41.256 & 380.876 \\
\hline 2015 & 561.01 & 3276.41 & 11852.4 & 792.76 & 41.652 & 391.592 \\
\hline
\end{tabular}

estimate future effects of a certain policy on the system. The overall goal of the model is not only to forecast the exact state of the modelled system, but also to explore how the system will evolve because of a specific policy. In this research, we focus on the effect of changes in economic and social variables on water consumption and vice versa. The model was simulated initially by using the production and water sectors considering a policy that assumes an average annual growth in the explanatory variables derived from the growth made during the last five years, 2002-2006. The simulated values of the six dependent variables are presented in 
Table 8. Naturally, a very large number of changes in the policy variables can be introduced into the model to produce other simulation results.

\section{CONCLUSION}

The main theme of this research is to adopt an economic approach for making the most of Jordan's water resources that will have a greater impact on enhancing water status in Jordan. Several interesting conclusions can be made. First, with regard to production sector, our findings indicate that a major effect can be attributed to the supply of water. Second, gross domestic product of agricultural, industrial and other sectors was found to be a highly significant factor in influencing the supply of water. Furthermore, the model concludes that priorities for making the most of Jordan's water resources should be given to options affecting water-supply strategy which relates the supply of water to the level of production. Other conclusions of importance in terms of future policies can also be drawn from Table 8. In particular, numerically generated simulation results tend to provide more importance to the water model. Finally, it should be emphasized that greater supply of water, when available, will lead to high economic growth.

\section{REFERENCES}

1. Lonergan, S.C. and D.B. Brooks, 1994. Watershed: The Role of Fresh Water in the Israeli-Palestinian Conflict. IDRC, Ottawa. ISBN 1552500977. http://www.idrc.ca/en/ev-9325-201-1-

DO TOPIC.html. Accessed on 30 September $200 \overline{8}$.

2. Jury, W. A. and Vaux, H.J. Jr. 2007. The Emerging Global Water Crisis: Managing Scarcity and Conflict Between Water Users, Advances in Agronomy, 95:1-76. DOI: 10.1016/S00652113(07)95001-4

3. Habab, M.S. and K. Al-Absi, 2004. Estimation of irrigation water demand function and its price elasticity in north and middle Jordan valley, Dirasat: Agric. Sci., 31: 239-248.

http://dar.ju.edu.jo/dirasatonline/getArticles.asp?art

$=10231020239$. Accessed on 30 September 2008 .
4. Al-Kadi, A.F. and A. Al-Nsour, 2004. Estimation of supply and demand functions for drinking water in Jordan, Dirasat: Agric. Sci., 31: 259-267.

http://dar.ju.edu.jo/dirasatonline/getArticles.asp?art $=10231020259$. Accessed on 30 September 2008 .

5. Central Bank of Jordan, 2007. Annual Report 2007, Vol. 44, Central Bank of Jordan, Amman. http://www.cbj.gov.jo/pages.php. Accessed on 30 September 2008.

6. Chen, H. and Yang, Z.F., 2009, Residential water demand model under block rate pricing: A case study of Beijing, China, Communications in Nonlinear Science and Numerical Simulation Vol. 14, Issue 5: 2462-2468, DOI:10.1016/j.cnsns.2007.12.013

7. Drécourt, J.P, Keijzer, M. and Hansen, P.F. 2002, A data mining approach to modelling of water supply assets, Urban Water, Vol. 2, Issue 4: 401414. DOI:10.1016/S1462-0758(02)00034-1

8. Capece, J. and Boumdian, L. 2007. Population Growth and Water Demand Model for Port LaBelle, Florida, Southern DataStream, Inc, http://hendryutilities.com/docs/boxes/PLUS_Popul ation_Study_070830.pdf. Accessed on 22 November 2008.

9. Mylopoulos, Y.A., A.K. Mentes and I. Theodossiou, 2004. Modeling residential water demand using household data: A cubic approach. Water Int'l., vol. 29, no. 1, pp. 105-113.

http://cat.inist.fr/?aModele $=$ afficheN\&cpsidt $=1560$ 2622. Accessed on 22 November 2008.

10. Kolokytha, E., Y. Mylopoulos and A. Mentes, 2002. Evaluating demand management aspects of urban water policy: A field survey in the city of Thessaloniki-Greece. Urban Water, Vol. 4, Issue 4: 391-400. DOI: 10.1016/S1462-0758(02)00024-9 